УДК 657.47(075.8)

JEL R40

Максименко Олеся

Александровна

студент магистратуры,

ФГБОУ ВО «Государственный

университет управления»,

г. Москва, Российская

Федерация

ORCID: 0000-0002-9247-876X

e-mail:sem.olesya.97@gmail.com

Olesya A. Maksimenko

Graduate student, State University

of Management, Moscow, Russia

ORCID: 0000-0002-9247-876X

e-mail:sem.olesya.97@gmail.com
КЛАССИФИКАЦИЯ ТРАНСПОРТНО-ЭКСПЕДИЦИОННЫХ 3ATPAT

Аннотация. Научно-обоснованная классификация затрат обеспечивает формирование релевантной информации о величине, структуре и содержании затрат организации. Необходимость классификации транспортно-экспедиционных затрат обусловлена требованияли поиска резервов минимизации расходов на продажу продукции (услуг). Повышение эффективности осуществления затрат является важнейшей управленческой задачей. Классификаиия транспортно-экспедиционных затрат дает возможность выделить в их структуре непроизводительные расходы и разработать систему управленческих мер по их минимизации, что приведет к увеличению прибыли и рентабельности. Существующие методические подходы к управленческому учету транспортно-экспедиционных затрат не позволяют сформировать единой научно-обоснованной классификации указанных затрат, выявить резервы их снижения на перспективу. В связи с этим иелью статьи является исследование теоретических основ классификации транспортно-экспедииионных затрат как объекта управленческого учета, выявление основных проблемных вопросов классификации затрат и внесение предложений в части ее совершенствования. Теоретической и методологической основой исследования явились работы российских и зарубежных специалистов в области организации управленческого учета. Основныли методами исследования, использованными при написании работы, явились метод теоретического системного анализа, монографический (описательный) метод.

Ключевые слова: классификация, транспортно-экспедиционные затраты, себестоимость, коммерческие расходы, оптимизация затрат, управленческий учет, налоговый учет, экспедиторские документы, производительные и непроизводительные затраты

Для цитирования: Максименко О.А. Классификация транспортно-экспедиционных затрат//Вестник университета. 2021. № 8. С. 122-126.

\section{CLASSIFICATION OF TRANSPORTATION AND FORWARDING COSTS}

Abstract. The scientifically-based classification of costs provides the formation of relevant information about the size, structure and content of the organization's costs. The need to classify freight forwarding costs is due to the requirements of searching for reserves to minimize the costs of selling products (services). Increasing the cost-effectiveness is the most important management task. The classification of freight forwarding costs makes it possible to identify unproductive expenses in their structure and develop a system of management measures to minimize them, which will lead to an increase in profit and profitability. The existing methodological approaches to the management accounting of freight forwarding costs do not allow us to form a single scientifically based classification of these costs, to identify reserves for their reduction in the future. In this regard, the purpose of the article is to study the theoretical foundations of the classification of freight forwarding costs as an object of management accounting, identify the main problematic issues of cost classification and make proposals for its improvement. The theoretical and methodological basis of the study was the publications of Russian and foreign specialists in the field of management accounting organization. The main research methods used in writing the work were the method of theoretical system analysis and the monographic (descriptive) method.

Keywords: classification, freight forwarding costs, prime cost, selling expenses, cost optimization, management accounting, tax accounting, forwarding documents, productive and unproductive costs

For citation: Maksimenko O.A. (2021) Classification of transportation and forwarding costs. Vestnik universiteta, no. 8 , pp. $122-126$. DOI: $10.26425 / 1816-4277-2021-8-122-126$

(c) Максименко О.А., 2021.

Статья доступна по лицензии Creative Commons «Attribution» («Атрибуция») 4.0. всемирная (http://creativecommons.org/licenses/by/4.0/).

(C) Maksimenko O.A., 2021.

This is an open access article under the CC BY 4.0 license (http://creativecommons.org/licenses/by/4.0/).

(c) (i) 


\section{Введение}

Классификация имеет первостепенное значение в части оптимизации затрат и выявления резервов снижения коммерческих расходов. Значительный удельный вес в составе расходов на продажу занимают транспортно-заготовительные и экспедиционные затраты. Указанная категория затрат имеет особую важность изза сложности выделения в их структуре производительных и непроизводительных расходов, экономически оправданных и неоправданных затрат в системе управленческого учета организации. Такое выделение является обязательным для поиска направлений их ликвидации. Не менее важным аспектом является развитие системы учета данных затрат, которая должна включать оценку затрат, способы отражения в учете, подробную классификацию по статьям и элементам, центрам ответственности и т. д., порядок отражения в бухгалтерском учете и бухгалтерской отчетности.

В статье проведен теоретический системный анализ данной категории затрат, рассмотрены особенности применения классификации затрат, основные проблемы классификации данной категории затрат, даны практические рекомендации по ее совершенствованию.

\section{Классификации транспортно-экспедиционных затрат в системе учета затрат}

Согласно «Инструкции по составу, учету и калькулированию затрат, включаемых в себестоимость перевозок (работ, услуг) предприятий автомобильного транспорта» (утв. Минтрансом РФ 29.08.1995) к транспортно-сбытовым затратам для целей управления производством принято относить:

- затраты по ведению документооборота экспедиторских документов (поручение экспедитору, экспедиторская расписка, складская расписка, накладные, акты);

- затраты на получение необходимых лицензий, разрешительных документов, экспертиз, заключений;

- затраты на обеспечение транспортной безопасности;

- затраты на получение специальных разрешений на движение транспортных средств, осуществляющих перевозки опасных грузов различных классов;

- затраты на получение специальных разрешений на движение транспортных средств, осуществляющих перевозки крупногабаритных и (или) тяжеловесных грузов;

- затраты на оформление переадресовки грузов;

- затраты по оформлению претензионной документации;

- затраты на подготовку отчета экспедитора (по требованию);

- затраты на перевозку грузов в местах общего и необщего пользования в пунктах отправления (на станциях, в портах и т. п.);

- затраты на выдачу грузов в пунктах назначения [6, 8,].

С позиции ведущих специалистов в сфере управленческого учета, если договорные обязательства по транспортировке груза экспедитор выполняет не единолично, а использует третье лицо, то деятельность экспедитора считается посреднической. В связи с этим посреднические затраты можно учитывать в составе транспортно-экспедиционных. К ним следует отнести:

- посреднические услуги в сфере перевозки грузов;

- посреднические услуги в сфере страхования грузов;

- посреднические услуги в сфере складского обеспечения транспортно-экспедиционной деятельности [1].

Ряд специалистов отмечают необходимость включения в состав транспортно-экспедиционных затрат таких неоднородных по содержанию затрат, как:

- потери, понесенные в связи с форс-мажорными обстоятельствами;

- штрафы, пени, неустойки [4].

В свою очередь, по нашему мнению, целесообразность включения этой группы затрат в состав транспортно-экспедиционных затрат отсутствует, так как по своему содержанию такие расходы можно отнести на убытки, что и подтверждается требованиями ПБУ 10/99 «Расходы организации» [4].

Необходимость выделения классификационного признака для целей производства и управления диктуется жесткими требованиями по установлению цен и тарифов на перевозочную деятельность сырья, материалов и промышленной продукции. Указанный классификационный признак может оказать существенное 
влияние на заключение внешнеэкономических контрактов, так как данная категория затрат может учитываться у покупателя или поставщика в зависимости от принятых базисных условий поставок товаров в соответствии с требованиями «Инкотермс» (англ. Incoterms, International Commercial Terms). В условиях действующих экономических санкций западных стран приведенный аргумент является существенным.

Далее, рассмотрим основные проблемы классификации транспортно-экспедиционных затрат по отношению к производству и управлению.

Существенной проблемой применения действующей классификации учета транспортно-экспедиционных затрат является несоответствие их требований основным положением Налогового кодекса Российской Федерации (далее - НК РФ), что обеспечивает своеобразный разрыв в методологии налогового и бухгалтерского учета затрат.

Одной из проблем классификации транспортно-экспедиционных затрат является отсутствие нормативного документа, определяющего особенности учета затрат и калькулирования себестоимости экспедиторских услуг в транспортной сфере. Такой пробел в законодательстве безусловно отрицательно сказывается на эффективности управления затратами и оптимизации данных расходов в данной сфере.

Другой, не менее значимой, проблемой классификации на организационном уровне является отсутствие практики разработки внутрифирменных стандартов управленческого учета и контроля транспортно-экспедиционных затрат. Необходимость разработки данных документов диктуется потребностью в строгой регламентации учетных процедур в отношении данных затрат - от ведения первичного учета до обобщения информации о транспортно-экспедиционных затратах в бухгалтерской или управленческой отчетности.

Безусловно, проблемой классификации транспортно-экспедиционных затрат является подтверждение целесообразности расходов для целей налогообложения прибыли. В частности, для отражения в налоговом учете транспортно-экспедиционных затрат в качестве принимаемых для целей налогообложения прибыли необходимо составить договор транспортной экспедиции таким образом, чтобы была подтверждена производственная или управленческая целесообразность данной операции (пункт 2 статьи 802 Гражданского кодекса РФ) [5].

Таким образом, осуществление экспедитором требований договора подтверждается еще и экспедиторскими документами, состав которых зависит от вида услуг, оказываемых экспедитором [2].

К экспедиторским документам нами рекомендуется относить:

- поручение экспедитору (определяет перечень и условия оказания экспедитором услуг);

- экспедиторская расписка (подтверждает факт получения груза от клиента).

Необходимо указать на то, что экспедиторская расписка не является достаточным документом для подтверждения в целях налогообложения прибыли расходов на доставку, что подтверждает Письмо УФНС России по городу Москве от 29.08.2008 № 20-12/082058. Складская расписка является основанием принятия экспедитором у клиента груза на складское хранение.

Некоторые специалисты считают, что основным документом, подтверждающим получение груза и факт отражения транспортно-экспедиционных затрат в бухгалтерском учете, является доверенность на получение груза по форме M-2 [7]. По-нашему мнению, такая позиция ошибочна, так как доверенность подтверждает не факт расходов и затрат, а факт получения груза, следовательно, ее нельзя считать основанием для отражения и списания транспортно-экспедиционных затрат в бухгалтерском учете. Возможно, сейчас назрела необходимость подготовки унифицированных форм первичных документов для отражения данной категории затрат в бухгалтерском учете.

Согласно Письму Министерства финансов РФ от 16.01.2018 № 03-03-06/1/1533 неотъемлемой частью договора транспортной экспедиции являются экспедиторские документы, а именно поручение экспедитору, экспедиторская расписка, складская расписка [3].

В целях подтверждения расходов при оказании услуг транспортной экспедиции в рамках главы 25 Налогового кодекса РФ достаточно любых документов, подтверждающих фактическое выполнение определенных договором экспедиции услуг.

Важной проблемой классификации транспортно-экспедиционных затрат является отсутствие выделения их производительной и непроизводительной (необязательной) части в структуре затрат. Необходимость определения непроизводительной части этих затрат диктуется по сути поиском необходимых резервов минимизации этих затрат в рамках управленческого анализа и достижения целевой себестоимости продукции, работ, услуг (запланированного уровня коммерческих расходов). 
Таким образом, для решения проблемы научно-обоснованной классификации транспортно-экспедиционных затрат для целей производства и управления авторы предлагают:

- расширить типовую номенклатуру транспортно-экспедиционных затрат за счет включения в действующую классификацию следующих их видов: затраты на посреднические услуги в сфере перевозки грузов; затраты на посреднические услуги в сфере страхования грузов, затраты на посреднические услуги в сфере складского обеспечения транспортно-экспедиционной деятельности;

- осуществлять деление данных затрат (ведение аналитического учета) на принимаемые для целей налогообложения прибыли и непринимаемые расходы;

- для достижения запланированного (целевого) уровня коммерческих расходов необходимо разделять транспортно-экспедиционные затраты на производительные и непроизводительные (убытки). При этом производительные включать в расходы на продажу, непроизводительные списывать напрямую на счет 99 «Прибыли и убытки» (как убытки);

- затраты в виде потерь, понесенных в связи с форс-мажорными обстоятельствами, штрафы, пени, неустойки относить не в состав транспортно-экспедиционных, а включать в состав прочих расходов организации на счет 91 «Прочие доходы и расходы»;

- рекомендовать коммерческим организациям транспортной сферы внедрить во все внутрифирменные стандарты учета раздел, посвященный классификации затрат. При этом внести соответствующие изменения в учетную политику организации.

\section{Заключение}

Таким образом, по результатам проведенного исследования следует считать транспортно-экспедиционные затраты важнейшим объектом управленческого учета, так как от их уровня и состава зависит величина коммерческих расходов организации и, как следствие, финансовые результаты деятельности организации в целом. Транспортно-экспедиционные затраты в структуре расходов на продажу имеют тенденцию к непрерывному росту и могут достигать до 50 \% в совокупных затратах транспортной организации, в связи с этим классификация затрат имеет первостепенное значение в части оптимизации расходов и выявления резервов их снижения.

В качестве основного признака классификации транспортно-экспедиционных затрат авторы предлагают применять классификацию по отношению к производству и управлению, так как именно этот признак обеспечивает наиболее полную номенклатуру затрат, дает возможность выделить производительную и непроизводительную часть, подтвердить целесообразность осуществления данных затрат для целей налогообложения прибыли.

В исследовании выделены основные проблемы классификации транспортно-экспедиционных затрат:

- подтверждение расходов для целей налогообложения прибыли;

- целесообразность включения потерь, понесенных в связи с форс-мажорными обстоятельствами, штрафов, пени, неустойки в состав данной группы;

- отсутствие системности в нормативно-правовом регулировании данных затрат;

- неоднородность затрат по отношению к себестоимости продукции (работ, услуг);

- отсутствие единого нормативного документа, определяющего особенности учета затрат и калькулирования себестоимости экспедиторских услуг;

- отсутствие практики разработки внутрифирменных стандартов оптимизации и управления транспортно-экспедиционными затратами;

- выделение производительной и непроизводительной части в данной категории затрат.

В качестве решения описанных выше проблем предложены необходимые рекомендации как в части внесений предложений в документооборот организации, так и в части изменения нормативно-правового регулирования учета транспортно-экспедиционных затрат.

Применение научно-обоснованной классификации транспортно-экспедиционных затрат позволит, по нашему мнению, сформировать объективную информацию о составе данных затрат в структуре коммерческих расходов, обеспечит возможность оперативного контроля за их величиной, позволит избежать неоправданных потерь в процессе реализации продукции (работ, услуг). 


\section{Библиографический список}

1. Баханькова, Е. Р. Бухгалтерский управленческий учет. - М.: ИЦ РИОР, ИНФРА-М, 2019. -255 с.

2. Вахрушева, О. Б. Бухгалтерский управленческий учет. - М.: Дашков и К, 2019. - 252 с.

3. Воронова, Е. Ю. Управленческий учет: Учебник для бакалавров. - М.: Юрайт, 2018. - 551 с.

4. Гаджиев, Н. Г., Коноваленко, С. А. Типичные ошибки и нарушения, выявляемые в учете затрат на производство и исчисление себестоимости продукции (работ, услуг) // Вестник Дагестанского государственного университета. Серия 3 : Общественные науки. -2020 . - Т. 35, № 4. - С. 7-19.

5. Керимов, В. Э. Бухгалтерский управленческий учет: Практикум. - М.: Дашков и К, 2017. - 100 с.

6. Орлова О. Е. Цели, методы и порядок распределения расходов // Руководитель автономного учреждения. - 2019. № 8. - С. 39-47.

7. Палий, В. Ф. Управленческий учет издержек и доходов (с элементами финансового учета). - М.: ИНФРА-М, 2017. -279 с.

8. Семенихин, В. В. Посреднические услуги. - 4-е изд., перераб. и доп. - М.: ГроссМедиа, РОСБУХ, 2020. -873 с.

\section{References}

1. Bakhankova E. R. Accounting management accounting, Moscow, ITs RIOR, INFRA-M, 2019, 255 p. (In Russian).

2. Vakhrusheva O. B. Accounting management accounting, Moscow, Dashkov i K, 2019, 252 p. (In Russian).

3. Voronova E. Yu. Managerial accounting: A textbook for bachelors, Moscow, Yurait, 2018, 551 p. (In Russian).

4. Gadzhiev N. G., Konovalenko S. A. Typical errors and violations detected in accounting for production costs and calculating the cost of products (works, services), Herald of Dagestan State University. Series 3: Social Sciences, 2020, vol. 35, no. 3, pp. 7-19. (In Russian).

5. Kerimov V. E. Accounting management accounting: Practicum, Moscow, Dashkov i K, 2017, 100 p. (In Russian).

6. Orlova O. E. Goals, methods and procedure for allocating expenses, Rukovoditel' avtonomnogo uchrezhdeniya, 2019, no. 8, pp. 39-47. (In Russian).

7. Palii V. F. Managerial accounting of costs and income (with elements of financial accounting), Moscow, INFRA-M, 2017, 279 p. (In Russian).

8. Semenikhin V. V. Intermediary services, 4th edition, revised and supplemented, Moscow, GrossMedia, ROSBUKH, 2020,873 p. (In Russian). 